\title{
The Hydrogen Sulfide Donor NaHS Delays Programmed Cell Death in Barley Aleurone Layers by Acting as an Antioxidant
}

\author{
Ying-Xin Zhang, ${ }^{1}$ Kang-Di Hu, ${ }^{1}$ Kai Lv, ${ }^{2}$ Yan-Hong Li, ${ }^{1}$ Lan-Ying Hu, ${ }^{1}$ Xi-Qi Zhang, \\ Long Ruan, ${ }^{2}$ Yong-Sheng Liu, ${ }^{1}$ and Hua Zhang ${ }^{1}$ \\ ${ }^{1}$ School of Biotechnology and Food Engineering, Hefei University of Technology, Hefei 230009, China \\ ${ }^{2}$ Anhui Academy of Agricultural Sciences, Hefei 230031, China \\ Correspondence should be addressed to Hua Zhang; hzhanglab@gmail.com
}

Received 18 November 2014; Revised 4 January 2015; Accepted 4 January 2015

Academic Editor: Guangdong Yang

Copyright (c) 2015 Ying-Xin Zhang et al. This is an open access article distributed under the Creative Commons Attribution License, which permits unrestricted use, distribution, and reproduction in any medium, provided the original work is properly cited.

$\mathrm{H}_{2} \mathrm{~S}$ is a signaling molecule in plants and animals. Here we investigated the effects of $\mathrm{H}_{2} \mathrm{~S}$ on programmed cell death (PCD) in barley (Hordeum vulgare L.) aleurone layers. The $\mathrm{H}_{2} \mathrm{~S}$ donor NaHS significantly delayed PCD in aleurone layers isolated from imbibed embryoless barley grain. NaHS at $0.25 \mathrm{mM}$ effectively reduced the accumulation of superoxide anion $\left(\cdot \mathrm{O}_{2}{ }^{-}\right)$, hydrogen peroxide $\left(\mathrm{H}_{2} \mathrm{O}_{2}\right)$, and malondialdehyde (MDA), promoted the activity of superoxide dismutase (SOD), guaiacol peroxidase (POD), catalase (CAT), and ascorbate peroxidase (APX), and decreased those of lipoxygenase (LOX) in isolated aleurone layers. Quantitative-PCR showed that NaHS treatment of aleurone tissue led to enhanced transcript levels of the antioxidant genes $H v S O D 1, H v A P X, H v C A T 1$, and $H v C A T 2$ and repressed transcript levels of $H v L O X$ (lipoxygenase gene) and of two cysteine protease genes $H v E P A$ and $H v C P 3-$ 31. NaHS treatment in gibberellic acid- (GA-) treated aleurone layers also delayed the PCD process, reduced the content of $\cdot \mathrm{O}_{2}{ }^{-}$, and increased POD activity while decreasing LOX activity. Furthermore, $\alpha$-amylase secretion in barley aleurone layers was enhanced by $\mathrm{NaHS}$ treatment regardless of the presence or absence of GA. These data imply that $\mathrm{H}_{2} \mathrm{~S}$ acted as an antioxidant in delaying PCD and enhances $\alpha$-amylase secretion regardless of the presence of GA in barley aleurone layers.

\section{Introduction}

Programmed cell death (PCD), a response of plants to biotic and abiotic stresses, can also occur during the normal course of development [1]. Cereal aleurone layers undergo gibberellic acid- (GA-) stimulated PCD process following germination and therefore provide a convenient model for studying PCD [2]. PCD in barley aleurone layers occurs only after cells become highly vacuolated and is accompanied with loss of plasma membrane integrity and increased cysteine protease activity [3]. However, the hallmarks of apoptosis in animal cells, including internucleosomal DNA ladders and formation of apoptotic bodies, are not observed in aleurone cells [4]. Reactive oxygen species (ROS) such as superoxide anion $\left(\cdot \mathrm{O}_{2}{ }^{-}\right)$, hydrogen peroxide $\left(\mathrm{H}_{2} \mathrm{O}_{2}\right)$, and hydroxyl radicals are key players in the PCD process in both plants and animals $[1,4,5]$. For instance, intracellular $\mathrm{H}_{2} \mathrm{O}_{2}$ overproduction or exogenous $\mathrm{H}_{2} \mathrm{O}_{2}$ application results in a rapid death in GA-treated aleurone protoplasts [6]. Antioxidant enzymes such as catalase (CAT), guaiacol peroxidase (POD), ascorbate peroxidase (APX), and superoxide dismutase (SOD) are responsible for ROS scavenging, thereby keeping homeostatic levels of ROS. PCD in plants is also accompanied by increased protease activity $[2,7]$. For instance, cysteine protease activation is instrumental in PCD of soybean cells, while ectopic expression of cystatin, a cysteine protease inhibitor gene, inhibits cysteine protease activity and blocks PCD [7]. What is more, the increase in cysteine protease and aspartic protease activities is also observed in GA-treated barley aleurone layers [2].

Hydrogen sulfide $\left(\mathrm{H}_{2} \mathrm{~S}\right)$, similar to nitric oxide $(\mathrm{NO})$ and carbon monoxide (CO), is an important endogenous gaseous signaling molecule in animal cells [8]. Accumulating evidence shows that $\mathrm{H}_{2} \mathrm{~S}$ is involved in various processes in plants, such as response to pathogen attack, seed germination, root organogenesis, abiotic stress tolerance, guard 
cell movement, and postharvest senescence of fruits and vegetables [9-17]. In particular, during abiotic stresses and postharvest storage, $\mathrm{H}_{2} \mathrm{~S}$ acts as an antioxidant to counteract excessive ROS to promote seed germination and alleviate postharvest senescence $[10,15,16]$. More recently, $\mathrm{H}_{2} \mathrm{~S}$ is found to delay PCD in GA-treated wheat aleurone layers by modulation of glutathione (GSH) and heme oxygenase 1 expression [18]. However, whether $\mathrm{H}_{2} \mathrm{~S}$ has a role in regulating PCD in barley aleurone layers treated with GA or not and whether ROS and ROS-scavenging enzymes participate in the role of $\mathrm{H}_{2} \mathrm{~S}$ are still unknown. In the present research, we find that the $\mathrm{H}_{2} \mathrm{~S}$ donor NaHS effectively delays PCD in barley aleurone layers regardless of the presence of GA, through the enhancement in antioxidant enzyme genes expression and antioxidant enzyme activity and decrease in protease gene expression.

\section{Materials and Methods}

2.1. Materials and Treatments. Grains of barley (Hordeum vulgare L.) were kindly supplied by Jiangsu Academy of Agricultural Sciences, Jiangsu Province, China. Grains were surface-sterilized as described by Chrispeels and Varner [19]. In brief, embryo end of the grain was removed, and fifteen half-grains were imbibed in distilled water at $25^{\circ} \mathrm{C}$ for $3 \mathrm{~d}$ on Petri dishes and further used for NaHS or gibberellic acid (GA) plus $\mathrm{CaCl}_{2}$ treatment. $\mathrm{H}_{2} \mathrm{~S}$ donor $\mathrm{NaHS}$ and $\mathrm{GA}$ were purchased from Sigma.

2.2. Cell Viability Analysis in Barley Aleurone Layers. Barley half-grains pretreated with water for $3 \mathrm{~d}$ were incubated in different concentrations of NaHS $(0,0.005,0.025,0.05,0.25$, or $0.5 \mathrm{mM}$ ) or $0.25 \mathrm{mM} \mathrm{NaHS}+5 \mu \mathrm{M} \mathrm{GA}$ (in $10 \mathrm{mM} \mathrm{CaCl}_{2}$ ) at $25^{\circ} \mathrm{C}$ for $5 \mathrm{~d}$ prior to isolation of aleurone layers from halfgrains. To determine the number of dead cells, three aleurone layers per treatment were stained with $0.4 \%$ trypan blue [20] for $10 \mathrm{~min}$ and observed with Nikon Eclipse 80 i fluorescence microscope (Nikon, Japan). The percentage of dead cells was determined by the calculation of blue or purple cells compared to the total number of cells in randomly selected fields from three different aleurone layers per treatment.

2.3. Detection of Reactive Oxygen Species Using Fluorescent Probe. A reactive oxygen species kit $2^{\prime}, 7^{\prime}$-dichlorodifluorescein diacetate (DCHF-DA) (Cayman Chemical, America) which is a fluorogenic probe in living cells was used to detect ROS content [21]. Three aleurone layers per treatment were rinsed with water three times and incubated with $5 \mu \mathrm{M}$ DCHF-DA for $20 \mathrm{~min}$ at $37^{\circ} \mathrm{C}$ in the dark according to manufacturer's instructions. The fluorescence of dichlorofluorescein DCF (excitation at $488 \mathrm{~nm}$, emission at $525 \mathrm{~nm}$ ) was observed using a Nikon Eclipse 80 i fluorescence microscope (Nikon, Japan). Nonstained aleurone layers were used as negative control. The experiment was repeated three times and similar results were obtained.

2.4. Determination of the Contents of Superoxide Anion, Hydrogen Peroxide, and Malondialdehyde. $\cdot \mathrm{O}_{2}{ }^{-}, \mathrm{H}_{2} \mathrm{O}_{2}$, and
MDA contents were measured according to the method in [22]. Embryoless half-grains were pretreated with sterile water for $3 \mathrm{~d}$ and incubated in sterile $\mathrm{H}_{2} \mathrm{O}, 0.25 \mathrm{mM} \mathrm{NaHS}$, and $0.25 \mathrm{mM} \mathrm{NaHS}+5 \mu \mathrm{M}$ GA. Three independent experiments with three replicates of 15 half-grains $(0.45 \pm 0.001 \mathrm{~g})$ were sampled for each treatment every $24 \mathrm{~h}$ until the fifth day.

2.5. Assays of the Activity of Antioxidant Enzymes and Lipoxygenase. Activity of SOD (EC 1.15.1.1), CAT (EC 1.11.1.6), APX (EC 1.11.1.11), and POD (EC 1.11.1.7) was determined according to García-Limones et al. [23] and that of LOX (EC 1.13.11.12) followed the description by Surrey [24]. Frozen grain samples $(0.45 \pm 0.001 \mathrm{~g})$ were homogenized with $1 \mathrm{~mL}$ of $200 \mathrm{mM}$ ice-cold phosphate buffer (pH 7.8) containing $1.0 \mathrm{mM}$ ethylenediaminetetraacetic acid (EDTA). The homogenate was centrifuged at $12,000 \mathrm{~g}$ at $4^{\circ} \mathrm{C}$ for $20 \mathrm{~min}$, and the supernatant was used for activity measurement.

For LOX, three independent replicates of 15 half-grains $(0.45 \pm 0.001 \mathrm{~g})$ in three independent experiments per treatment were homogenized with $1 \mathrm{~mL}$ of $200 \mathrm{mM}$ phosphate buffer ( $\mathrm{pH}$ 6.0). The homogenate was centrifuged at 15,000 $\mathrm{g}$ at $4^{\circ} \mathrm{C}$ for $10 \mathrm{~min}$, and the supernatant was used for the enzyme assay. The assay mixture in a total volume of $3 \mathrm{~mL}$ contained $200 \mathrm{mM}$ borate buffer ( $\mathrm{pH}$ 6.0), 0.25\% linoleic acid, $0.25 \%$ tween- 20 , and $50 \mu \mathrm{L}$ of enzyme extract. The reaction was carried out at $25^{\circ} \mathrm{C}$ for $5 \mathrm{~min}$, and the activity of LOX was determined in the presence of linoleic acid by monitoring the changes in absorbance at $234 \mathrm{~nm}$.

2.6. Quantitative PCR Analysis. Total RNA was isolated from five aleurone layers using the plant RNeasy kit (Forgene, China) according to the manufacturer's instructions. Total RNA (500 ng) from different treatments was used for firststrand cDNA synthesis in a $20 \mu \mathrm{L}$ reaction volume containing $4 \mu \mathrm{L} 5 \times$ PrimeScript RT Master Mix (TaKaRa). Quantitative PCR was performed using a StepOnePlus Real-Time PCR System (Applied Biosystems, Foster City, CA, USA) with SYBR Premix Ex Taq (TaKaRa Bio Inc, China) according to the manufacturer's instructions. cDNA was amplified by PCR using the following primers: HvActin (accession number: LOC548170) forward (5'-TCTCACGGACTCCCTTT- $\left.3^{\prime}\right)$ and HvActin reverse ( $5^{\prime}$-CACTGAGCACGATGTTTC-3'); HvCAT1 (accession number: HVU20777) forward ( $5^{\prime}$-AAGACCGTTTCCTCCAGC- $\left.3^{\prime}\right)$ and reverse (5'ATTCAAGGCTACCGCACA- $3^{\prime}$ ); HvCAT2 (accession number: HVU20778) forward ( $5^{\prime}$-CGCCTTCAAGCCCAACCCA- $\left.3^{\prime}\right)$ and reverse $\left(5^{\prime}\right.$-TTCTCCCTCTTTCCAACCAC$\left.3^{\prime}\right)$; HvSOD1 (accession number: JQ364454) forward $\left(5^{\prime}\right.$ CGATAGCCAGATTCCTTTG- ${ }^{\prime}$ ) and reverse ( $5^{\prime}$-TCCACCAGCATTTCCAGTA-3'); HvAPX (accession number: AJ006358) forward ( $5^{\prime}$-CTACTACTGCTGCTACTATGCG- $\left.3^{\prime}\right)$ and reverse $\left(5^{\prime}\right.$-CACTGACAGCGTTCAAGGTAT$\left.3^{\prime}\right)$; HvLOX (accession number: AJ966349) forward $\left(5^{\prime}\right.$ CCGCTCTGACCCATTTCG- $3^{\prime}$ ) and reverse (5'-TGCTCCTTGACCTCCACCTT- $3^{\prime}$ ); HvICY (accession number: AJ536590) forward ( $5^{\prime}$-TCGTCGTGCCGTTTACTC- $\left.3^{\prime}\right)$ and 
reverse ( $5^{\prime}$-TTGGCCTTCTTGTTGTGC-3'); HvEPA (accession number: HVU94591) forward ( $5^{\prime}$-CCCGTGTCGGTGGCAATA-3 $\left.{ }^{\prime}\right)$ and reverse (5'-GCATCCTGATGTAACCCTTCTC-3'); HvCP3-31 (accession number: AB377533) forward $\left(5^{\prime}\right.$-ACAACCTCCGCTACATCG- $\left.3^{\prime}\right)$ and reverse $\left(5^{\prime}\right.$-CCCTTCTTCCTCCAGTCG-3'). Relative gene expression was presented as values relative to control HvActin transcript level, after normalization to the control HvActin transcript levels.

2.7. Assays of Secreted $\alpha$-Amylase Activity. Embryoless barley half-grains were incubated in distilled water for $3 \mathrm{~d}$ and then treated with various concentrations of $\mathrm{NaHS}$ in presence or absence of $20 \mu \mathrm{M} \mathrm{GA}$ and $10 \mathrm{mM} \mathrm{CaCl}_{2}$.

Agar-starch medium (containing 4\% agar and 0.1\% starch) was used to detect $\alpha$-amylase activity secreted by aleurone layers in NaHS treatment without $\mathrm{GA}$ and $\mathrm{CaCl}_{2}$ for $24 \mathrm{~h}$. Aleurone layers which were prepared as described above were placed on agar-starch medium for $16 \mathrm{~h}$ after which the agar-starch was stained with $0.6 \% \mathrm{I}_{2}$ and $6 \% \mathrm{KI}$ solution to show digested starch zones. The experiment was repeated three times and similar results were obtained.

Twenty embryoless half-grains were imbibed in distilled water at $25^{\circ} \mathrm{C}$ for $3 \mathrm{~d}$ on Petri dishes and incubated in Erlenmeyer flasks which contained different concentrations of $\mathrm{NaHS}$ in $20 \mu \mathrm{M} \mathrm{GA}$ and $10 \mathrm{mM} \mathrm{CaCl}_{2}$. Incubation medium was sampled after $24 \mathrm{~h}$ and heated at $70^{\circ} \mathrm{C}$ for $15 \mathrm{~min}$ to eliminate $\beta$-amylase activity. Amylase secreted to the medium was visualized in $10 \%$ native PAGE gels by the starch-iodine method according to [25]. To visualize $\alpha$-amylase activity, the gel was incubated at $25^{\circ} \mathrm{C}$ for $30 \mathrm{~min}$ in $50 \mathrm{mM} \mathrm{PBS} \mathrm{(pH} \mathrm{7.0)}$ containing $1 \%$ boiled soluble starch. After being washed three times with distilled water, the gel was stained with $0.6 \% \mathrm{I}_{2}$ and $6 \% \mathrm{KI}$ solution. The experiment was repeated three times and similar results were obtained.

The DNS method for the determination of secreted $\alpha$ amylase activity in medium was performed in $0.01 \mathrm{M}$ sodium acetate buffer, $\mathrm{pH}$ 5.4. The reaction mixture containing $1 \%$ soluble starch was incubated at $25^{\circ} \mathrm{C}$ for $5 \mathrm{~min}$ without substrate. Then, the reaction was initiated by adding the substrate and was continued for an additional $10 \mathrm{~min}$ at $37^{\circ} \mathrm{C}$. The reaction was terminated and hydrolysis was determined with 3,5-dinitrosalicylic acid reagent as modified by Noelting and Bernfeld [26].

2.8. Statistical Analysis. Statistical significance in all experiments was tested by one-way analysis of variance (ANOVA), and the results are expressed as the mean values \pm standard deviation (SD) of three independent experiments with three replicates for each. Fisher's least significant differences (LSD) were calculated following a significant $(P<0.01$ or $P<0.05)$ $t$-test.

\section{Results}

3.1. Programmed Cell Death in Barley Aleurone Layers Is Delayed by the $\mathrm{H}_{2} \mathrm{~S}$ Donor NaHS. To test the effect of $\mathrm{H}_{2} \mathrm{~S}$ on the PCD process, water-pretreated barley half-grains were incubated in different concentrations of NaHS for 5 days. Aleurone layers are isolated from half-grains and stained with trypan blue to visualize dead cells. NaHS treatments ranging from 0.005 to $0.5 \mathrm{mM}$ significantly decrease cell death compared with water controls (Figures 1(a) and 1(b)). Only $9 \%$ of cells die in aleurone layers treated with $0.25 \mathrm{mM}$ NaHS while approximately $67 \%$ of cells of aleurone layers incubated in water undergo PCD. As shown in Figure 1, $\mathrm{NaHS}$ at $0.25 \mathrm{mM}$ is most effective in delaying PCD in barley aleurone layers, and this concentration is used in subsequent experiments.

A time course of cell death in aleurone layers treated with $0.25 \mathrm{mM} \mathrm{NaHS}$ is shown in Figures $1(\mathrm{c})$ and $1(\mathrm{~d})$. After 7 days incubation in water, about $90 \%$ aleurone cells are dead in contrast to only $45 \%$ cell death in NaHS-treated layers. Together, these findings show that barley aleurone cells undergo PCD naturally in the absence of GA and that the $\mathrm{H}_{2} \mathrm{~S}$ donor NaHS effectively delays the PCD process.

3.2. NaHS Treatment Reduces the Accumulation of Reactive Oxygen Species in Non-GA-Treated Barley Aleurone Layers. Because ROS are tightly associated with the promotion of PCD in barley aleurone cells [6], we examine the contents of $\cdot \mathrm{O}_{2}^{-}, \mathrm{H}_{2} \mathrm{O}_{2}$, and MDA in non-GA-treated barley aleurone layers in the presence and absence of NaHS. As shown in Figure $2(\mathrm{a}), \cdot \mathrm{O}_{2}{ }^{-}$content in control barley aleurone layers accumulates rapidly during the 5 days of incubation. However, $\cdot \mathrm{O}_{2}{ }^{-}$content in NaHS-treated layers accumulates slowly until day 3 and keeps stable on day 5 .

The assay of $\mathrm{H}_{2} \mathrm{O}_{2}$ shows that layers incubated in NaHS produce less $\mathrm{H}_{2} \mathrm{O}_{2}$ than those incubated in water (Figure 2(b)). $\mathrm{H}_{2} \mathrm{O}_{2}$ content increases rapidly in control aleurone layers during the whole incubating time, whereas a slower increase in $\mathrm{H}_{2} \mathrm{O}_{2}$ content was observed in NaHS treatment on the first two days followed by a plateau.

MDA is determined as an index of lipid peroxidation. As shown in Figure 2(c), MDA content increases rapidly in water controls until day 4 followed by a decrease. In contrast, $\mathrm{NaHS}$ treatment significantly lowers the level of MDA (Figure 2(c)).

We use the ROS-sensitive fluorescent probe DCHF-DA to visualize the production of ROS in barley aleurone layers (Figure 2(d)). Fluorescence from layers which are incubated in 0.05 and $0.25 \mathrm{mM}$ NaHS is much less intense than water controls. More weak fluorescence is detected in tissue incubated in $0.25 \mathrm{mM}$ NaHS.

3.3. Effects of NaHS on Antioxidant Enzymes and Lipoxygenase in Non-GA-Treated Barley Aleurone Layers. We examine the activity of the ROS metabolizing enzymes SOD, POD, CAT, APX, and LOX in barley aleurone layers that are incubated in $0.25 \mathrm{mM} \mathrm{NaHS}$ and water (Figure 3). The activity of SOD increases to maximum on day 3 and then declines in NaHStreated layers. In contrast, SOD activity in water controls fluctuates slightly up to day 3 followed by a significant decrease (Figure 3(a)).

Figure 3(b) shows changes in POD activity in NaHStreated and water control layers. NaHS significantly increases POD activity on day 1 and remains high until day 4 . 


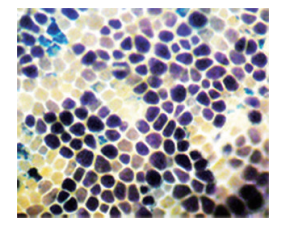

0

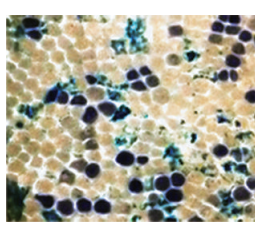

0.05

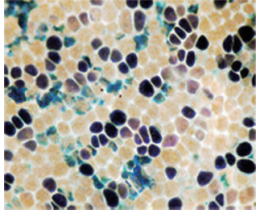

0.005

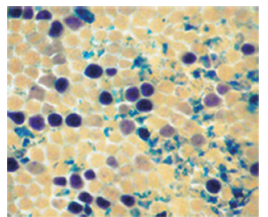

0.25

$(\mathrm{mM})$

(a)

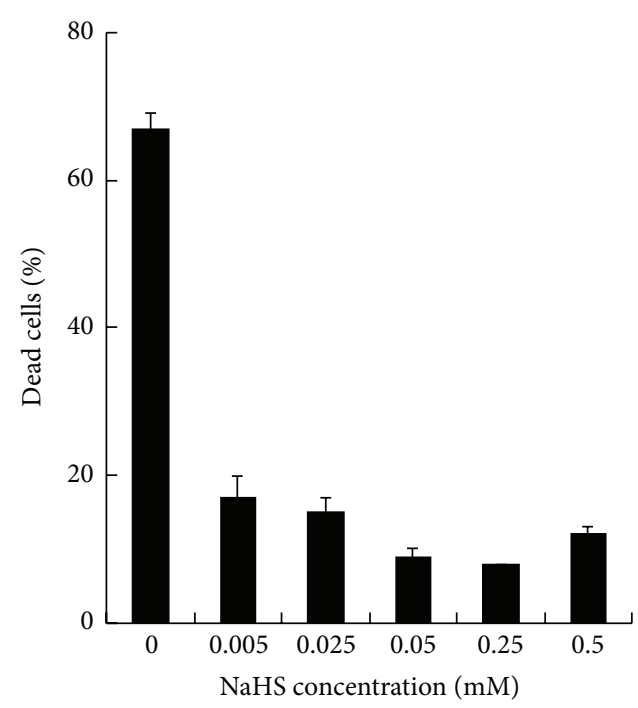

(b)
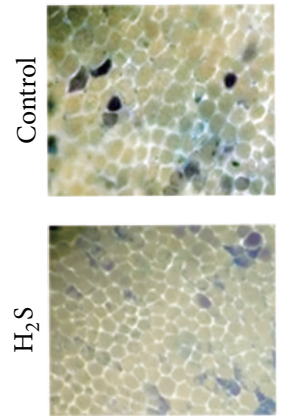

$0 \mathrm{~d}$
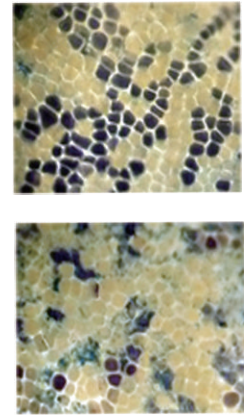

$3 \mathrm{~d}$
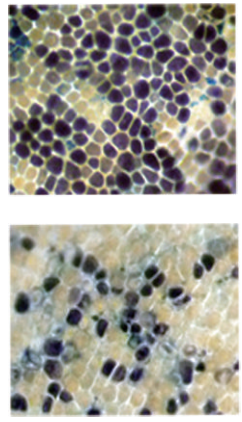

$5 d$

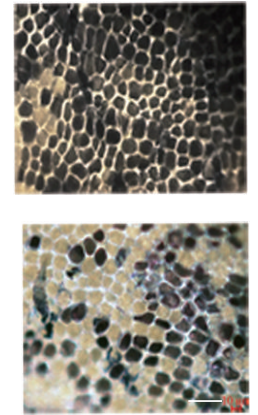

$7 \mathrm{~d}$

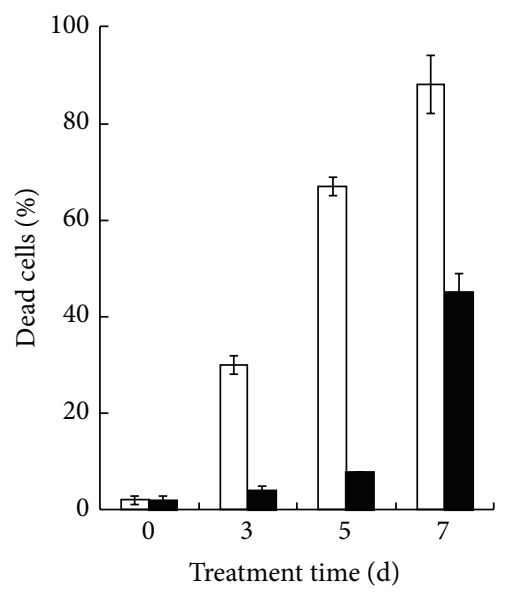

Control

- $\mathrm{H}_{2} \mathrm{~S}$

(c)

(d)

Figure 1: Effect of $\mathrm{H}_{2} \mathrm{~S}$ donor NaHS on cell viability in barley aleurone layers. ((a), (b)) Aleurone layers are incubated in different concentrations of NaHS $(0,0.005,0.025,0.05,0.25$, and $0.5 \mathrm{mM})$ for $5 \mathrm{~d}$ at $25^{\circ} \mathrm{C}$. After staining with trypan blue, the images are obtained by light microscopy with blue or purple indicating dead cells. ((c), (d)) Time course of PCD in barley aleurone layers treated with NaHS $\left(\mathrm{H}_{2} \mathrm{~S}\right)$ or water (Control). Aleurone layers are incubated in $0.25 \mathrm{mM} \mathrm{NaHS}$ or water for $0,1,3,5$, and $7 \mathrm{~d}$ at $25^{\circ} \mathrm{C}$ and are stained with trypan blue. Digital images of barley aleurone layers ((a), (c)) and percentages of dead cells ((b), (d)) are shown. Bar, $50 \mu \mathrm{m}$. Data are means \pm SD of three different aleurone layers per treatment.

In comparison, POD activity in water controls increases gradually and peaks on day 3 followed by a sharp decline. NaHS treatment maintains significantly higher levels of POD activity compared with water control during the whole treatment time. APX activity increases during the first 3 days of incubation and peaks on day 3 followed by a decrease in both NaHS-treated and water controls. However, APX activity in NaHS treatment is always significantly higher than that of control (Figure 3(c)).

Changes in CAT activity are shown in Figure 3(d). In both NaHS and water controls, CAT activity increases gradually up to day 3 and then decreases sharply. However, CAT activity from NaHS-treated layers is always significantly higher than those in control layers.

Figure 3(e) shows the changes in LOX activity in barley aleurone layers. LOX activity in water control increases dramatically and peaks on day 3 followed by a decrease. In contrast, NaHS treatment significantly decreases LOX activity, being about $50 \%$ of that of water control on day 3 .

3.4. Transcript Analysis of HvSOD1, HvCAT1, HvCAT2, HvLOX, Cysteine Protease (HvCP3-31 and HvEPA), and Cystatin (HvICY) in Non-GA-Treated Barley Aleurone Layers. We examine the expression of HvSOD1, HvCAT1, HvCAT2, 


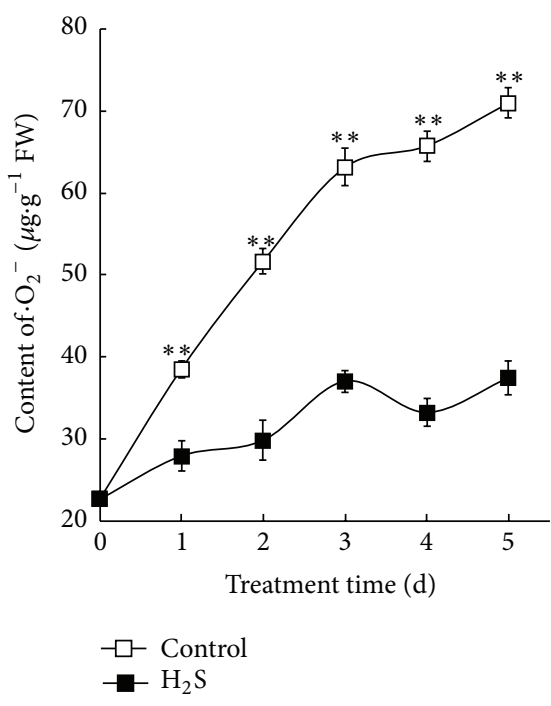

(a)

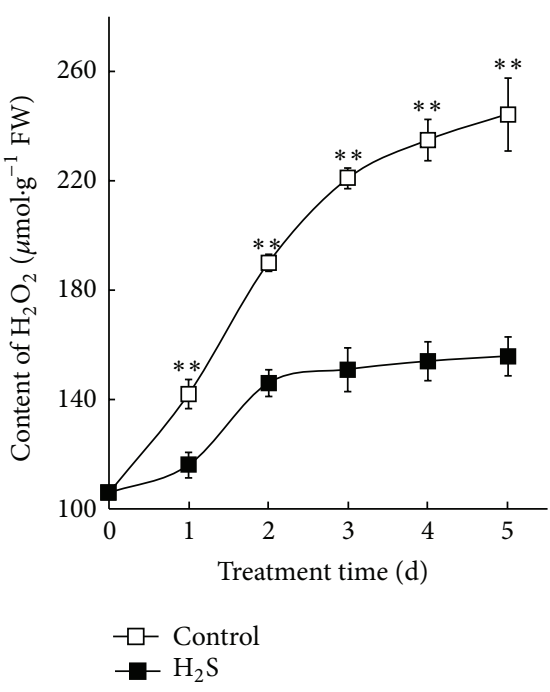

(b)

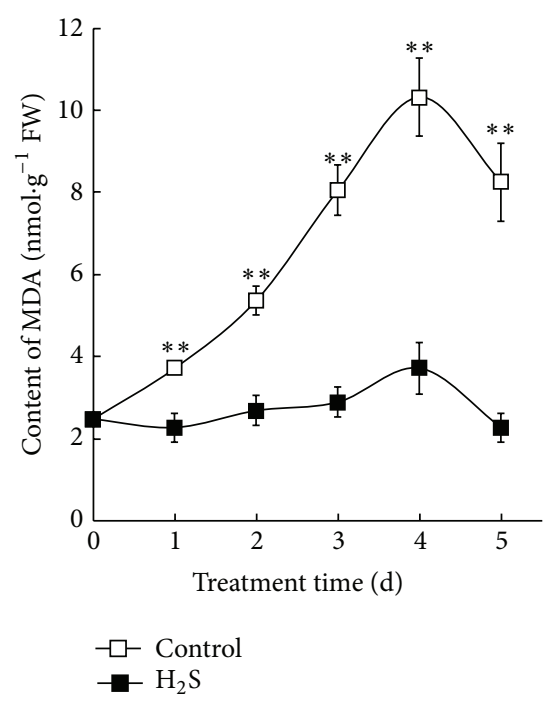

(c)
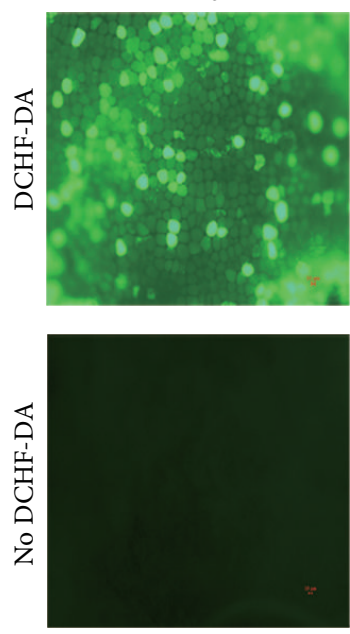

(mM)

0.05
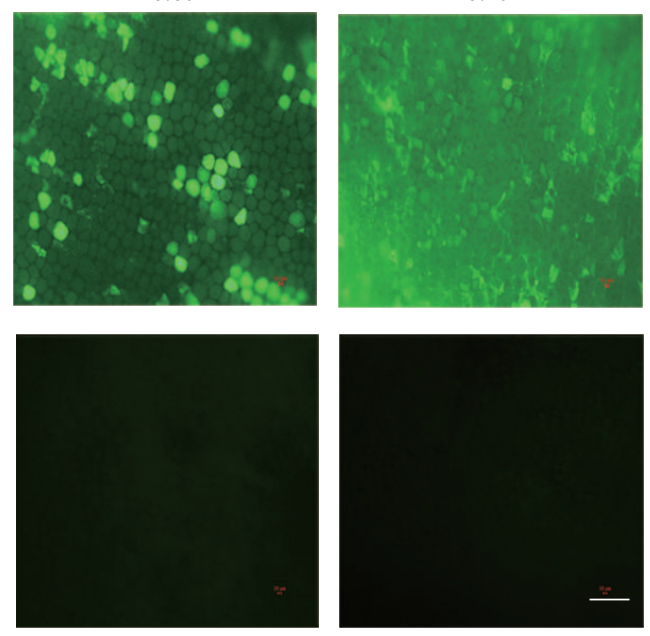

(d)

Figure 2: Effects of NaHS on the contents of $\cdot \mathrm{O}_{2}{ }^{-}$(a), $\mathrm{H}_{2} \mathrm{O}_{2}$ (b), and MDA (c) in barley aleurone layers. Aleurone layers treated with 0, 0.05 , and $0.25 \mathrm{mM}$ NaHS for $1 \mathrm{~d}$ are incubated DCHF-DA and are observed by fluorescence microscopy (d). Bar, $100 \mu \mathrm{m}$. Data are expressed as means \pm SD of three independent experiments with three replicates of 15 grains per treatment. The symbols $*$ and $* *$ mean significant difference at $P<0.05$ and $P<0.01$ between NaHS $\left(\mathrm{H}_{2} \mathrm{~S}\right)$ and water (control) treatment, respectively.

$H v L O X$, the cysteine proteases $H v C P 3-31$ and $H v E P A$, and cystatin $(\mathrm{H} v \mathrm{ICY})$ in NaHS-treated barley aleurone layers and water controls (Figure 4). Compared with water controls, NaHS induces higher expression of HvSOD1, HvAPX, $H v C A T 1$, and HvCAT2 on days 1 and 5. HvLOX expression increases in water control layers on days 1 and 5 compared with day 0 , while NaHS treatment sustains lower transcript of $H v L O X$ than water control, especially on day 5. PCD in barley aleurone layers is accompanied with increased cysteine protease activity [3]. Accordingly, we determine the expression of the cysteine proteinases HvEPA and HvCP3-31 and the cystatin $H v I C Y$ in NaHS treatment and water control. The expression of HvEPA and HvCP3-31 increases in water controls on days 1 and 5, whereas their expression is much lower in NaHS-treated tissue. The expression of $\mathrm{HvICY}$ was enhanced in NaHS-treated layers, whereas less transcript of $\mathrm{HvICY}$ is observed in water controls.

3.5. NaHS Delays PCD in GA-Treated Barley Aleurone Layers. PCD in barley aleurone layers is tightly regulated by GA and abscisic acid (ABA). We therefore assess whether $\mathrm{H}_{2} \mathrm{~S}$ can ameliorate PCD in GA-treated barley aleurone layers. As shown in Figure 5(a), the accumulation of dead cells increases rapidly from 24 to $96 \mathrm{~h}$ in GA-treated barley aleurone layers, whereas $0.25 \mathrm{mM}$ NaHS treatment significantly delays the rate of PCD. After incubation for $96 \mathrm{~h}$, about $90 \%$ cells in 


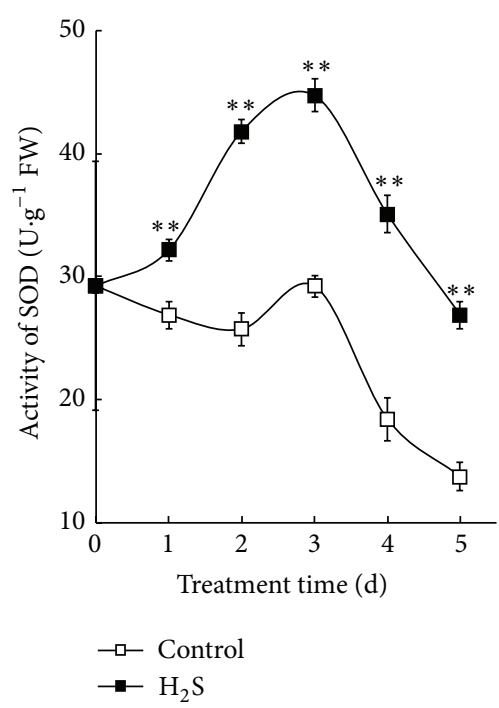

(a)

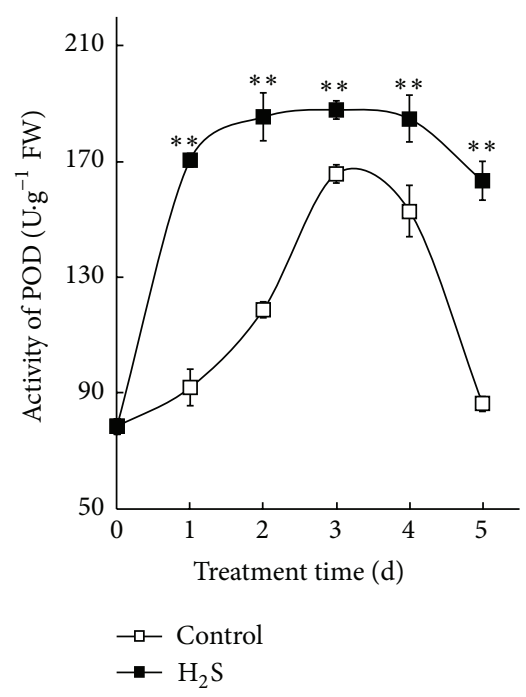

(b)

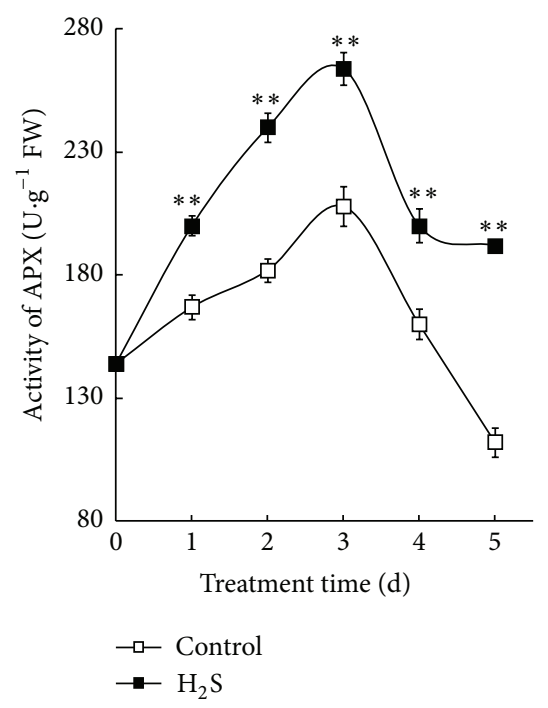

(c)

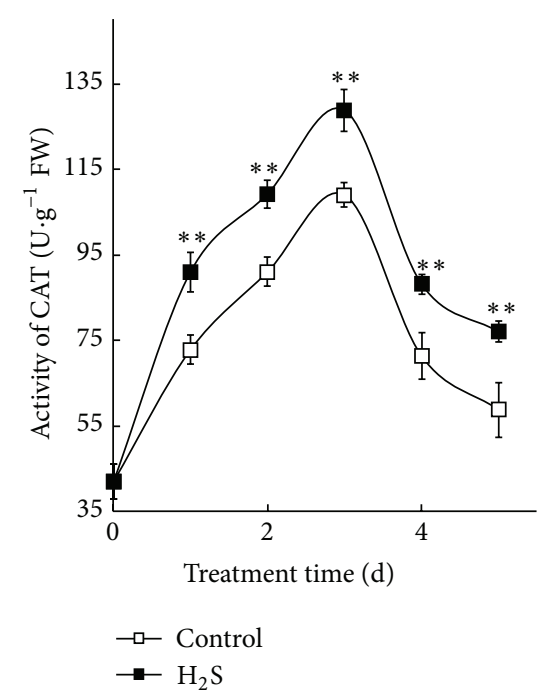

(d)

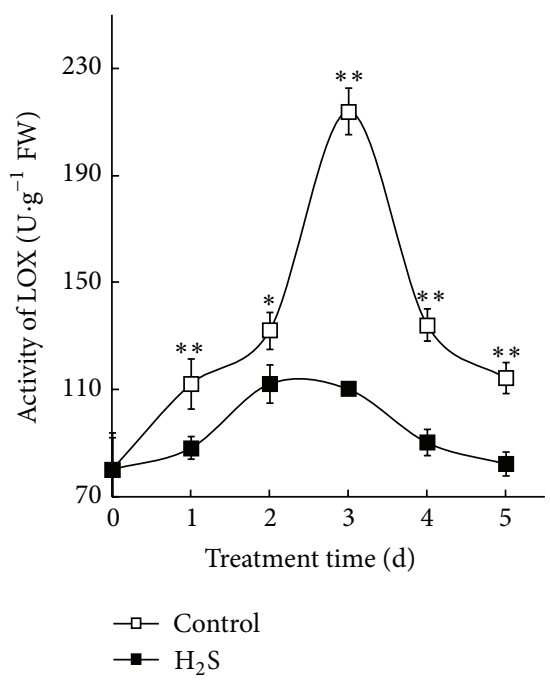

(e)

FIGURE 3: Effects of NaHS on the activity of SOD (a), POD (b), APX (c), CAT (d), and LOX (e) in barley aleurone layers. Data are expressed as means \pm SD of three independent experiments with three replicates of 15 grains per treatment. The symbols $*$ and $* *$ mean significant difference at $P<0.05$ and $P<0.01$ between control and T, respectively.

GA-treated layers are dead, while half of cells are still alive in NaHS-treated layers (Figure 5(b)). In water control, much less cells undergo PCD compared with the counterpart of GA and GA plus NaHS.

Determination of $\cdot \mathrm{O}_{2}{ }^{-}$content shows that NaHS treatment maintains lower levels of $\cdot \mathrm{O}_{2}{ }^{-}$in GA-treated barley aleurone layers (Figure 5(c)). After a rapid increase during the first 2 days of incubation, the content of $\mathrm{O}_{2}{ }^{-}$in GAtreated layers decreases till day 4 . In contrast, $\cdot \mathrm{O}_{2}{ }^{-}$content in NaHS plus GA treatment increases more slowly until day 3. A comparable but lower $\cdot \mathrm{O}_{2}{ }^{-}$content was observed in water control compared with NaHS plus GA treatment.

Figure 5(d) shows the effect of $\mathrm{H}_{2} \mathrm{~S}$ on POD activity in GA-treated barley aleurone layers. In both NaHS treatment and GA control, POD activity in GA-treated barley aleurone layers increases gradually up to day 3 and day 2, respectively, and decreases thereafter. However, the activity of POD in NaHS-treated aleurone layers is always significantly higher than those in water controls and GA treatment alone.

Figure 5(e) shows that NaHS treatment maintains lower levels of LOX activity compared with water control during the first 2 days of GA treatment. LOX activity in GA treatment increases dramatically on day 1 followed by a gradual decrease, while, in NaHS-treated tissue, the activity increases more slowly till day 3 followed by a decline. After day 3, LOX activity in NaHS plus GA is higher than that in GA treatment.

3.6. $\mathrm{H}_{2} \mathrm{~S}$ Donor Promotes $\alpha$-Amylase Secretion in Barley Aleurone Layers Regardless of GA. Secretion of $\alpha$-amylase is 

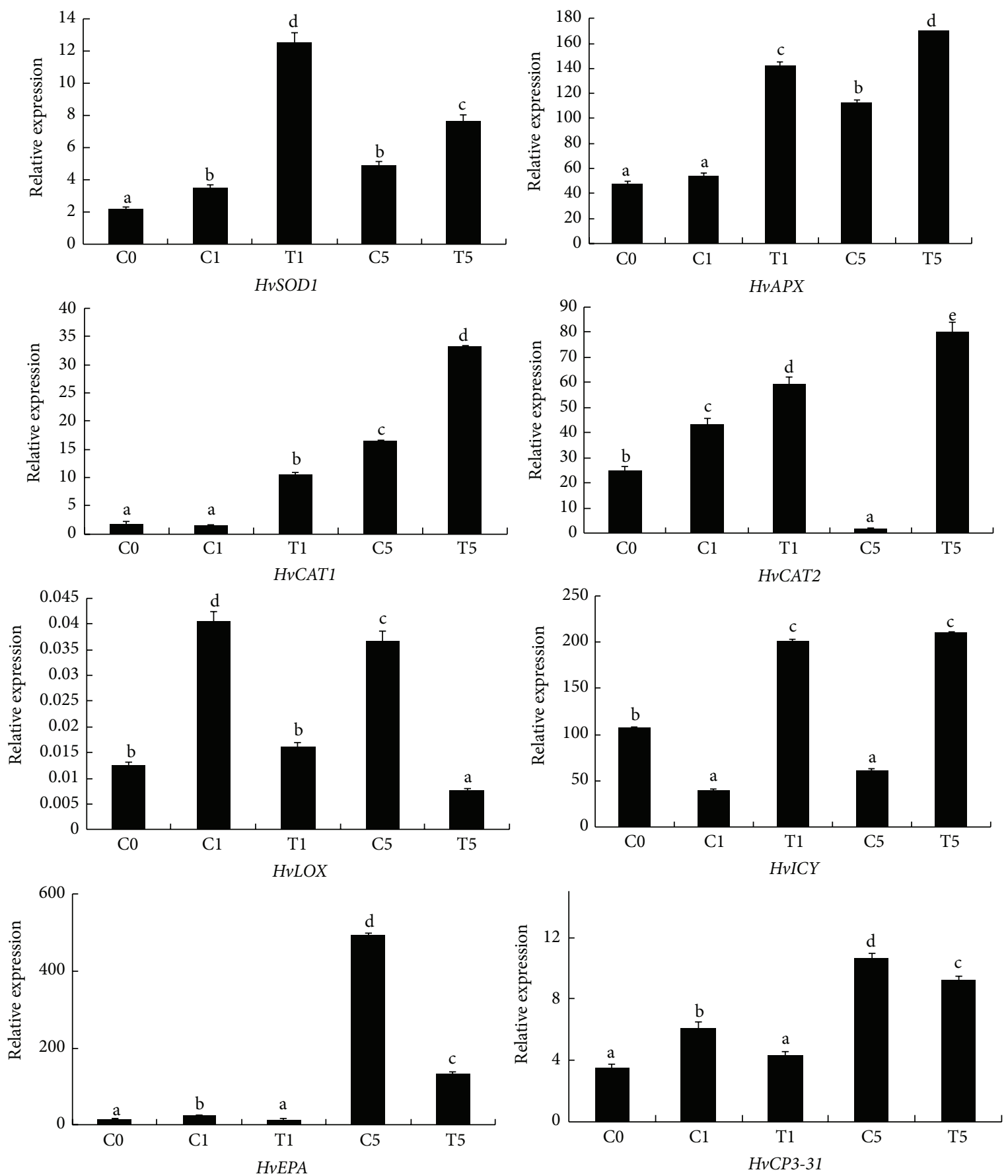

Figure 4: Effects of $\mathrm{H}_{2} \mathrm{~S}$ on the expression of HvSOD1, HvCAT1, HvCAT2, HvLOX, cystatin (HvICY), and the cysteine proteases HvCP3-31 and HvEPA in barley aleurone layers. Aleurone layers are incubated in NaHS (T) or water (C) and total RNA is obtained at 0,1 , and $5 \mathrm{~d}$. Means and SD values are calculated from three independent experiments. Within each identified gene, bars with different letters are significantly different in comparison with the corresponding control at $P<0.01$ according to Fisher's least significant differences (LSD).

a characteristic response of aleurone cells to GA. We therefore test whether the ameliorating effect of $\mathrm{H}_{2} \mathrm{~S}$ on PCD affects the release of $\alpha$-amylase. As shown in Figure 6(a), NaHS promotes $\alpha$-amylase release in water-treated aleurone layers. In the presence of GA, NaHS treatment also enhances $\alpha$-amylase release from barley aleurone layers (Figure $6(\mathrm{~b})$ ) with $0.5 \mathrm{mM}$ NaHS exhibiting optimal effect. Figure 6(c) shows the time changes in $\alpha$-amylase secretion in water control, GA-treated aleurone layers, and GA plus $0.25 \mathrm{mM}$ NaHS treatment. The accumulation of $\alpha$-amylase in incubation medium in GAtreated layers increases and peaks on day 3 followed by a plateau but addition of $0.25 \mathrm{mM}$ NaHS brings about a more rapid increase till day 4 followed by a decrease on day 5 (Figure 6(c)). The activity of $\alpha$-amylase released following 

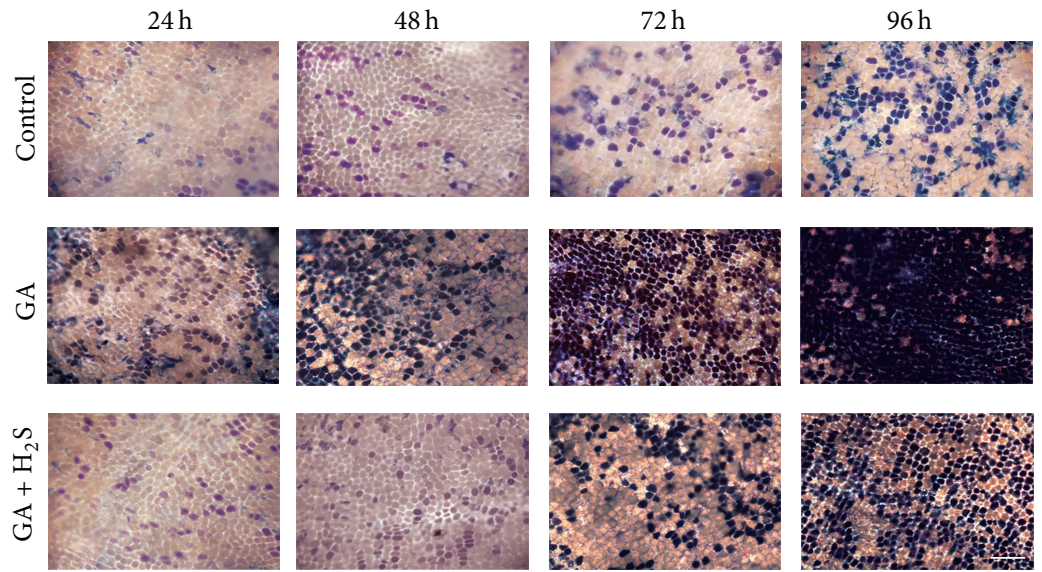

(a)
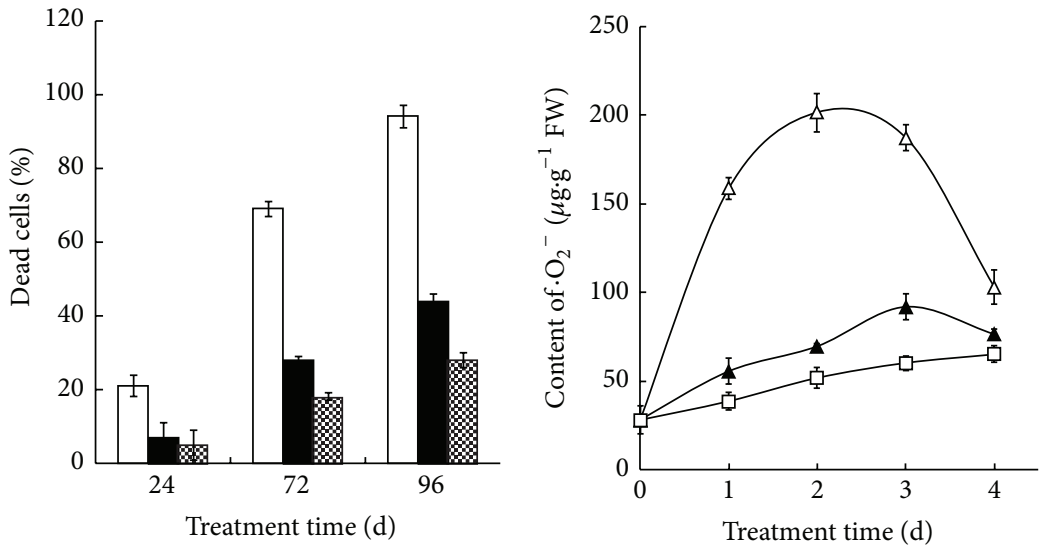

$$
\text { a } \mathrm{GA}+\mathrm{H}_{2} \mathrm{~S}
$$$$
-\triangle \text { GA }
$$$$
\rightarrow \mathrm{GA}+\mathrm{H}_{2} \mathrm{~S}
$$$$
\rightarrow-\text { Control }
$$

(b)

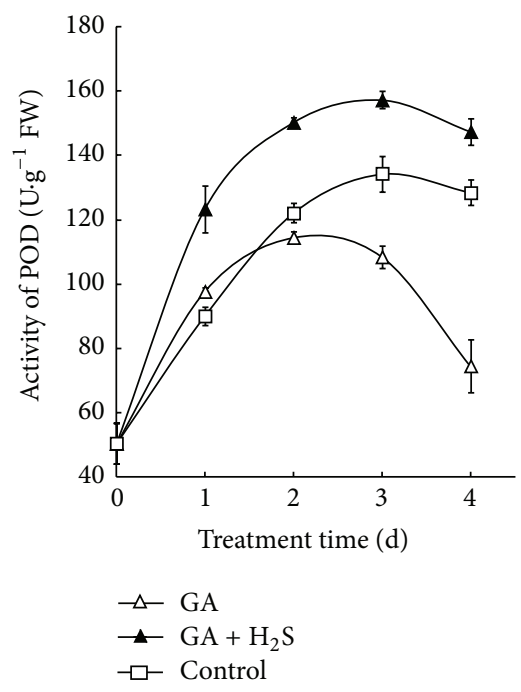

(d) (c)

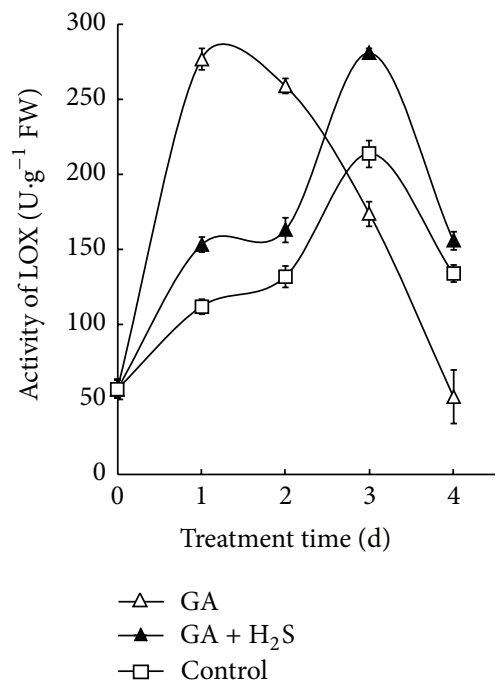

(e)

Figure 5: NaHS delays PCD in GA-treated barley aleurone layers. Aleurone layers are incubated in water, GA, or GA $+\mathrm{NaHS}\left(\mathrm{GA}+\mathrm{H}_{2} \mathrm{~S}\right)$ and, after being stained with trypan blue, images are obtained by light microscopy (a) and the percentage of dead cells is shown in (b). Content of $\cdot \mathrm{O}_{2}{ }^{-}$(c), activity of POD (d), and LOX (e) are measured on $0,1,2,3$, and $4 \mathrm{~d}$. Bar, $100 \mu \mathrm{m}$. Data in (c) and (d) are expressed as means \pm SD of three independent experiments with three replicates of 15 grains per treatment. 


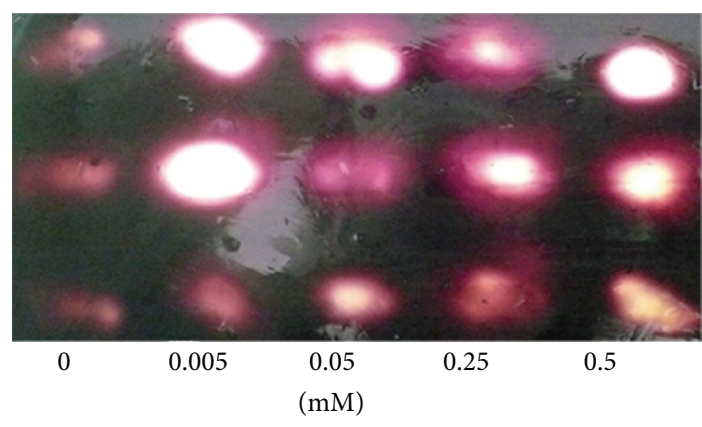

(a)

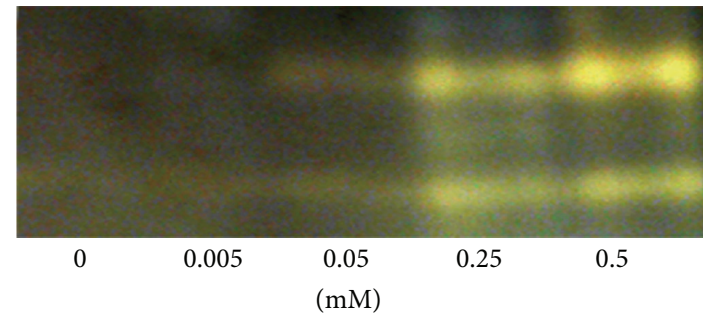

(b)

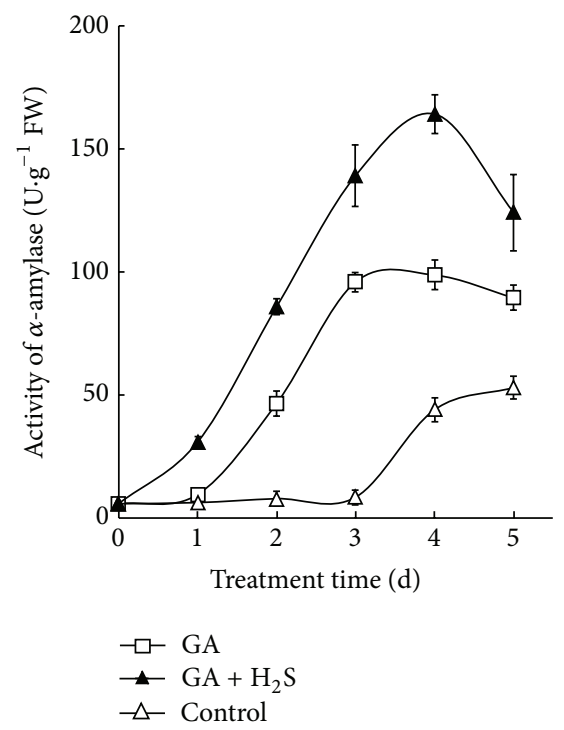

(c)

FIGURE 6: NaHS increases the activity of $\alpha$-amylase in incubation medium of barley aleurone layers in the absence (a) and presence ((b), (c)) of GA. Barley aleurone layers isolated from treated embryoless half grains are incubated in $0,0.005,0.05,0.25$, or $0.5 \mathrm{mM} \mathrm{NaHS}$ for $24 \mathrm{~h}$ ((a), (b)). After incubation, aleurone layers are placed on agar-starch medium (containing $4 \%$ agar and $0.1 \%$ starch) for $16 \mathrm{~h}$. Agar plates are stained with $\mathrm{I}_{2}$-KI solution to detect the activity of $\alpha$-amylase (a). (b) shows native PAGE analysis of $\alpha$-amylase activity in incubation medium surrounding the aleurone layers. (c) indicates secreted $\alpha$-amylase activity in incubation medium surrounding barley aleurone layers treated with water (control), GA, or GA $+\mathrm{NaHS}\left(\mathrm{GA}+\mathrm{H}_{2} \mathrm{~S}\right)$ at different times of incubation. Data in (c) are expressed as means $\pm \mathrm{SD}$ of three independent experiments with three replicates of 20 embryoless half grains per treatment.

GA + NaHS treatment is significantly higher than that of layers incubated only in GA during the whole treatment time. As expected, much lower $\alpha$-amylase activity was only observed in water control after 3 days of incubation. Together, this result indicates that $\mathrm{H}_{2} \mathrm{~S}$ delays PCD in barley aleurone layers and meanwhile promotes $\alpha$-amylase release regardless of the presence of GA.

\section{Discussion}

$\mathrm{H}_{2} \mathrm{~S}$ participates in multiple processes in plants [27]. In this paper, we show that $\mathrm{H}_{2} \mathrm{~S}$ delays PCD in barley aleurone layers regardless of the presence or absence of GA. In the absence of GA, PCD in barley aleurone layers is evident on day 3 of incubation, while $\mathrm{H}_{2} \mathrm{~S}$ delays PCD at an optimal concentration of $0.25 \mathrm{mM}$ (Figure 1). Consistent with the reports that GA accelerates PCD process in barley aleurone layers, GA treatment triggers cell death in about $90 \%$ aleurone cells at $72 \mathrm{~h}$ (Figure 5(a)). GA-induced cell death is slowed by the addition of NaHS and this $\mathrm{H}_{2} \mathrm{~S}$ donor also prolongs the phase of $\alpha$-amylase production in GA-treated layers. The promoting effect of NaHS on $\alpha$-amylase synthesis and its prolongation of cell survival indicate that $2.5 \mathrm{mM}$ NaHS does not affect aleurone cell function.

ROS, such as $\cdot \mathrm{O}_{2}{ }^{-}$and $\mathrm{H}_{2} \mathrm{O}_{2}$, are inducers of PCD in plant and animal cells [1]. It is reported that the peroxidation of membrane lipids and damage to the plasma membrane can occur when the rate of ROS production overcomes the cells' ability for scavenging ROS [27]. Overproduction of ROS and oxidative damage are universal events in PCD in plant cells [28]. In this paper, we show that the content of $\cdot \mathrm{O}_{2}{ }^{-}$increases in parallel with cell death in GA-treated layers (Figure 5(c)). In non-GA-treated layers, the burst of $\cdot \mathrm{O}_{2}^{-}$and $\mathrm{H}_{2} \mathrm{O}_{2}$ and 
the accumulation of MDA are also accompanied by PCD (Figure 2). These results suggest that ROS play a key role both in GA-treated [29] and in non-GA-treated aleurone layers (Figures 2(a), 2(b), and 5(c)).

Aleurone cells contain a suite of ROS-metabolizing enzymes. GA-induced PCD in layers is accompanied by a decline in activity of ROS metabolizing enzymes which leads to increased susceptibility of aleurone cells to ROS [29]. A novel aspect of our work is that NaHS treatment effectively reduces the accumulation of ROS in barley aleurone layers regardless the presence of GA (Figures 2 and 5), thereby delaying PCD process in these cells. We propose that the $\mathrm{H}_{2} \mathrm{~S}$ donor reduces ROS accumulation in layers by increasing the activity of ROS-scavenging enzymes. The data in present study show that $\mathrm{H}_{2} \mathrm{~S}$ treatment maintains significantly higher POD activity in GA-treated layers (Figure 5(d)) and higher SOD, POD, CAT, and APX activity in non-GA-treated layers (Figure 3). The increased activity of ROS-scavenging enzymes in NaHS-treated likely promotes the cell's ability to metabolize ROS. In addition, LOX activities which are responsible for lipid peroxidation are downregulated in NaHS-treated aleurone layers at early stage of treatment (Figures 3(e) and 5(e)). Meanwhile, quantitative-PCR analysis shows that expression of $H v S O D 1, H v A P X, H v C A T 1$, and $H v C A T 2$ genes in non-GA-treated layers is maintained at higher levels in NaHS treatment compared with water controls (Figure 4). Consistent with lower LOX activity in NaHS-treated aleurone layers, the accumulation of LOX transcripts is also reduced (Figure 4). In summary, $\mathrm{H}_{2} \mathrm{~S}$ slows down ROS-induced PCD in barley aleurone layers probably by enhancing the activity and expression of ROS-scavenging enzymes and reducing the peroxidation of membrane lipids.

Consistently, Xie et al. [18] found that $\mathrm{H}_{2} \mathrm{~S}$ delayed GAtriggered PCD in wheat aleurone layers by increasing GSH content and heme oxygenase-1 gene expression. Here we provide evidence that $\mathrm{H}_{2} \mathrm{~S}$ can alleviate both natural $\mathrm{PCD}$ and GA-triggered PCD through the modulation of antioxidant enzyme activities and their expression. Compared with the slow natural PCD process, the present study also confirms the pivotal role of GA in triggering PCD (Figure 5).

The role of ROS in GA and ABA signaling in barley aleurone cells is recently clarified [30], in which they found that the production of $\mathrm{H}_{2} \mathrm{O}_{2}$, a type of ROS, was induced by GA in aleurone cells but suppressed by ABA. Furthermore, exogenous $\mathrm{H}_{2} \mathrm{O}_{2}$ appeared to promote the induction of $\alpha$ amylases by GA by promoting the expression of GAMyb and $\alpha$-amylase genes, whereas antioxidants suppressed the induction of $\alpha$-amylase. Unexpectedly, we found that $\mathrm{H}_{2} \mathrm{~S}$ reduces ROS accumulation and delays PCD process in barley aleurone layers in the presence or absence of GA and meanwhile promotes the secretion of $\alpha$-amylase, suggesting that the antioxidant $\mathrm{H}_{2} \mathrm{~S}$ works through an unknown way to regulate $\alpha$-amylase secretion and antioxidants do not always suppress the induction of $\alpha$-amylase. Besides, the activation of $\alpha$ amylase by $\mathrm{H}_{2} \mathrm{~S}$ in the absence of GA implies that $\alpha$-amylase can be secreted independent of GA signaling pathway. Therefore, the present findings advance our knowledge on the relations between PCD process and $\alpha$-amylase secretion and the independence of $\alpha$-amylase secretion and GA pathway.

The activation of cysteine proteases was instrumental in the PCD of soybean cells, while cystatin, an endogenous cysteine protease inhibitor gene, inhibited cysteine protease activity and blocked PCD in these cells [7]. In this paper, we show that $\mathrm{H}_{2} \mathrm{~S}$ downregulates the transcriptions of two barley cysteine proteinases, $H v E P A$ and $H v C P 3-31$, in nonGA-treated barley aleurone layers, thereby delaying cell component degradation and PCD process.

\section{Conclusion}

In summary, we report the role of $\mathrm{H}_{2} \mathrm{~S}$ in delaying PCD in barley aleurone layers regardless of the presence or absence of GA without repressing $\alpha$-amylase induction, suggesting that the function of $\mathrm{H}_{2} \mathrm{~S}$ may be universal in regulating plant $\mathrm{PCD}$. PCD in plant cells is regulated by many internal and external factors, such as the hormones (GA and ABA), $\mathrm{Ca}^{2+}$, ROS, and $\mathrm{NO}$ [6]. It will be interesting to know whether $\mathrm{H}_{2} \mathrm{~S}$ is involved in other signals and how $\alpha$-amylase is induced by $\mathrm{H}_{2} \mathrm{~S}$ in the presence or absence of GA in cereal aleurone cells.

\section{Conflict of Interests}

The authors declare that there is no conflict of interests regarding the publication of this paper.

\section{Authors' Contribution}

Ying-Xin Zhang and Kang-Di Hu contributed equally to this work.

\section{Acknowledgments}

The authors acknowledge Russell Jones, University of California at Berkeley, for editing the paper. This work was supported by the Natural Science Foundation of China (nos. 31271803, 31301820, 31300133, and 31470013), the Scientific Research Foundation for Returned Overseas Chinese Scholars (SRF for ROCS, MOE), the Natural Science Foundations of Anhui Province (11040606M85), and the Anhui Provincial Education Department (nos. 2012AJZR0028, ZD200910).

\section{References}

[1] T. Jabs, "Reactive oxygen intermediates as mediators of programmed cell death in plants and animals," Biochemical Pharmacology, vol. 57, no. 3, pp. 231-245, 1999.

[2] A. Fath, P. Bethke, V. Beligni, and R. Jones, "Active oxygen and cell death in cereal aleurone cells," Journal of Experimental Botany, vol. 53, no. 372, pp. 1273-1282, 2002.

[3] A. Fath, P. Bethke, J. Lonsdale, R. Meza-Romero, and R. Jones, "Programmed cell death in cereal aleurone," Plant Molecular Biology, vol. 44, no. 3, pp. 255-266, 2000.

[4] P. C. Bethke, J. E. Lonsdale, A. Fath, and R. L. Jones, "Hormonally regulated programmed cell death in barley aleurone cells," The Plant Cell, vol. 11, no. 16, pp. 1033-1045, 1999. 
[5] P. E. Hockberger, T. A. Skimina, V. E. Centonze et al., "Activation of flavin-containing oxidases underlies light-induced production of $\mathrm{H}_{2} \mathrm{O}_{2}$ in mammalian cells," Proceedings of the National Academy of Sciences of the United States of America, vol. 96, no. 11, pp. 6255-6260, 1999.

[6] P. C. Bethke and R. L. Jones, "Cell death of barley aleurone protoplasts is mediated by reactive oxygen species," The Plant Journal, vol. 25, no. 1, pp. 19-29, 2001.

[7] M. Solomon, B. Belenghi, M. Delledonne, E. Menachem, and A. Levine, "The involvement of cysteine proteases and protease inhibitor genes in the regulation of programmed cell death in plants," The Plant Cell, vol. 11, no. 3, pp. 431-443, 1999.

[8] R. Wang, "Two's company, three's a crowd: can $\mathrm{H}_{2} \mathrm{~S}$ be the third endogenous gaseous transmitter?" The FASEB Journal, vol. 16, no. 13, pp. 1792-1798, 2002.

[9] E. Bloem, A. Riemenschneider, J. Volker et al., "Sulphur supply and infection with Pyrenopeziza brassicae influence L-cysteine desulphydrase activity in Brassica napus L.," Journal of Experimental Botany, vol. 55, no. 406, pp. 2305-2312, 2004.

[10] H. Zhang, L.-Y. Hu, K.-D. Hu, Y.-D. He, S.-H. Wang, and J.P. Luo, "Hydrogen sulfide promotes wheat seed germination and alleviates oxidative damage against copper stress," Journal of Integrative Plant Biology, vol. 50, no. 12, pp. 1518-1529, 2008.

[11] H. Zhang, J. Tang, X.-P. Liu et al., "Hydrogen sulfide promotes root organogenesis in Ipomoea batatas, Salix matsudana and Glycine max," Journal of Integrative Plant Biology, vol. 51, no. 12, pp. 1086-1094, 2009.

[12] Z. P. Jin, J. J. Shen, Z. J. Qiao, G. D. Yang, R. Wang, and Y. X. Pei, "Hydrogen sulfide improves drought resistance in Arabidopsis thaliana," Biochemical and Biophysical Research Communications, vol. 414, no. 3, pp. 481-486, 2011.

[13] Z. P. Jin, S. W. Xue, Y. N. Luo et al., "Hydrogen sulfide interacting with abscisic acid in stomatal regulation responses to drought stress in Arabidopsis," Plant Physiology and Biochemistry, vol. 62, pp. 41-46, 2013.

[14] C. García-Mata and L. Lamattina, "Hydrogen sulphide, a novel gasotransmitter involved in guard cell signalling," New Phytologist, vol. 188, no. 4, pp. 977-984, 2010.

[15] L.-Y. Hu, S.-L. Hu, J. Wu et al., "Hydrogen sulfide prolongs postharvest shelf life of strawberry and plays an antioxidative role in fruits," Journal of Agricultural and Food Chemistry, vol. 60, no. 35, pp. 8684-8693, 2012.

[16] S.-P. Gao, K.-D. Hu, L.-Y. Hu et al., "Hydrogen sulfide delays postharvest senescence and plays an antioxidative role in freshcut kiwifruit," HortScience, vol. 49, no. 10, pp. 1385-1392, 2013.

[17] S.-P. Li, K.-D. Hu, L.-Y. Hu et al., "Hydrogen sulfide alleviates postharvest senescence of broccoli by modulating antioxidant defense and senescence-related gene expression," Journal of Agricultural and Food Chemistry, vol. 62, no. 5, pp. 1119-1129, 2014.

[18] Y. Xie, C. Zhang, D. Lai et al., "Hydrogen sulfide delays GAtriggered programmed cell death in wheat aleurone layers by the modulation of glutathione homeostasis and heme oxygenase-1 expression," Journal of Plant Physiology, vol. 171, no. 2, pp. 53-62, 2014.

[19] M. J. Chrispeels and J. E. Varner, "Gibberellic acid enhanced synthesis and release of $\alpha$-amylase and ribonuclease by isolated barley and aleurone layers," Plant Physiology, vol. 42, no. 3, pp. 398-406, 1967.

[20] J. R. Tennant, "Evaluation of the trypan blue technique for determination of cell viability," Transplantation, vol. 2, pp. 685$694,1964$.
[21] M. Tsuchiya, M. Suematsu, and H. Suzuki, "In vivo visualization of oxygen radical-dependent photoemission," Methods in Enzymology, vol. 233, pp. 128-140, 1994.

[22] R. F. del Maestro, J. Björk, and K.-E. Arfors, "Increase in microvascular permeability induced by enzymatically generated free radicals: I. In vivo study," Microvascular Research, vol. 22, no. 3, pp. 239-254, 1981.

[23] C. García-Limones, A. Hervás, J. A. Navas-Cortés, R. M. Jiménez-Díaz, and M. Tena, "Induction of an antioxidant enzyme system and other oxidative stress markers associated with compatible and incompatible interactions between chickpea (Cicer arietinum L.) and Fusarium oxysporum f. sp. ciceris," Physiological and Molecular Plant Pathology, vol. 61, no. 6, pp. 325-337, 2002.

[24] K. Surrey, "Spectrophotometric method for determination of lipoxidase activity," Plant Physiology, vol. 39, no. 1, pp. 65-70, 1964.

[25] G. G. Collins, C. F. Jenner, and L. G. Paleg, "The metabolism of soluble nucleotides in wheat aleurone layers treated with gibberellic acid," Plant P hysiology, vol. 49, no. 3, pp. 404-410, 1972.

[26] G. Noelting and P. Bernfeld, "Sur les enzymes amylolytiqucs III. La $\beta$-amylase: dosage d'activité et contrôle de l'absence d' $\alpha$ amylase," Helvetica Chimica Acta, vol. 31, no. 1, pp. 286-290, 1948.

[27] M. Lisjak, T. Teklic, I. D. Wilson, M. Whiteman, and J. T. Hancock, "Hydrogen sulfide: environmental factor or signalling molecule?" Plant, Cell and Environment, vol. 36, no. 9, pp. 16071616, 2013.

[28] M. C. de Pinto, A. Paradiso, P. Leonetti, and L. de Gara, "Hydrogen peroxide, nitric oxide and cytosolic ascorbate peroxidase at the crossroad between defence and cell death," The Plant Journal, vol. 48, no. 5, pp. 784-795, 2006.

[29] A. Fath, P. C. Bethke, and R. L. Jones, "Enzymes that scavenge reactive oxygen species are down-regulated prior to gibberellic acid-induced programmed cell death in barley aleurone," Plant Physiology, vol. 126, no. 1, pp. 156-166, 2001.

[30] Y. Ishibashi, T. Tawaratsumida, K. Kondo et al., "Reactive oxygen species are involved in gibberellin/abscisic acid signaling in barley aleurone cells," Plant Physiology, vol. 158, no. 4, pp. 17051714, 2012. 


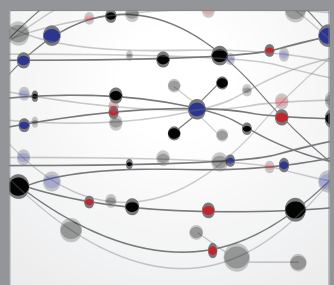

The Scientific World Journal
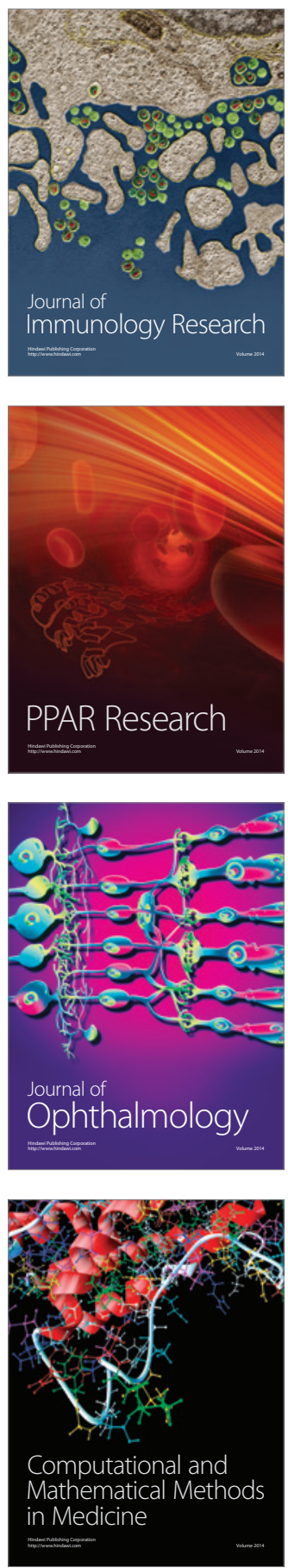

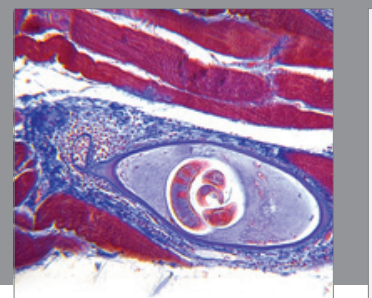

Gastroenterology

Research and Practice
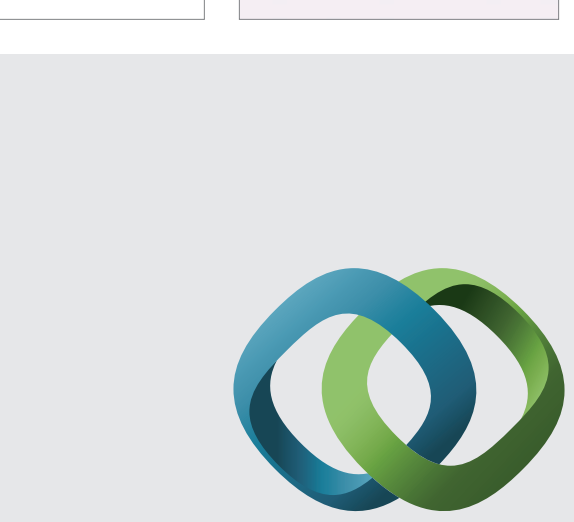

\section{Hindawi}

Submit your manuscripts at

http://www.hindawi.com
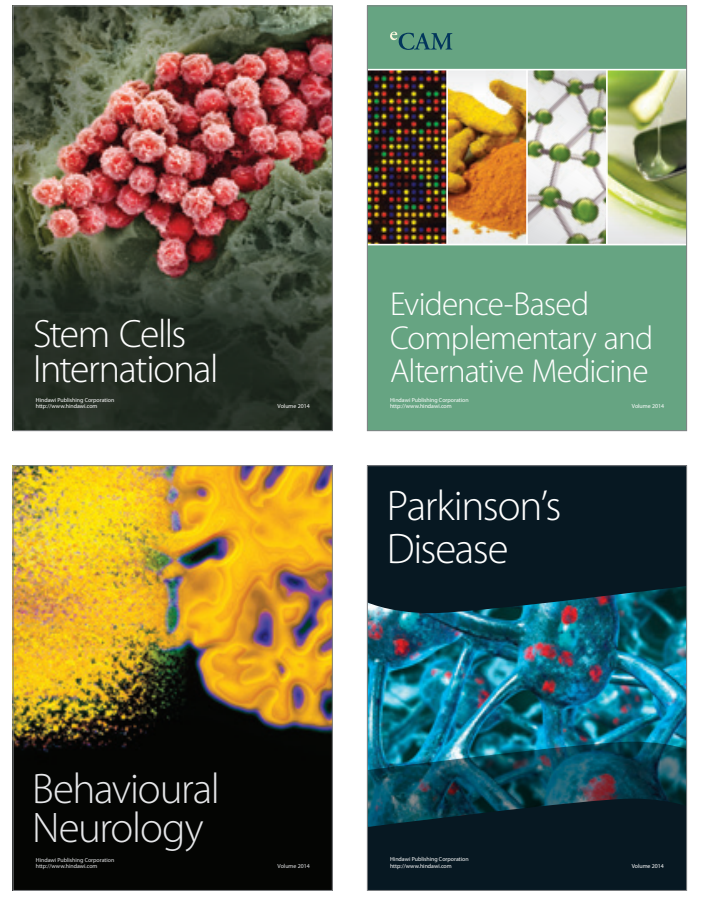
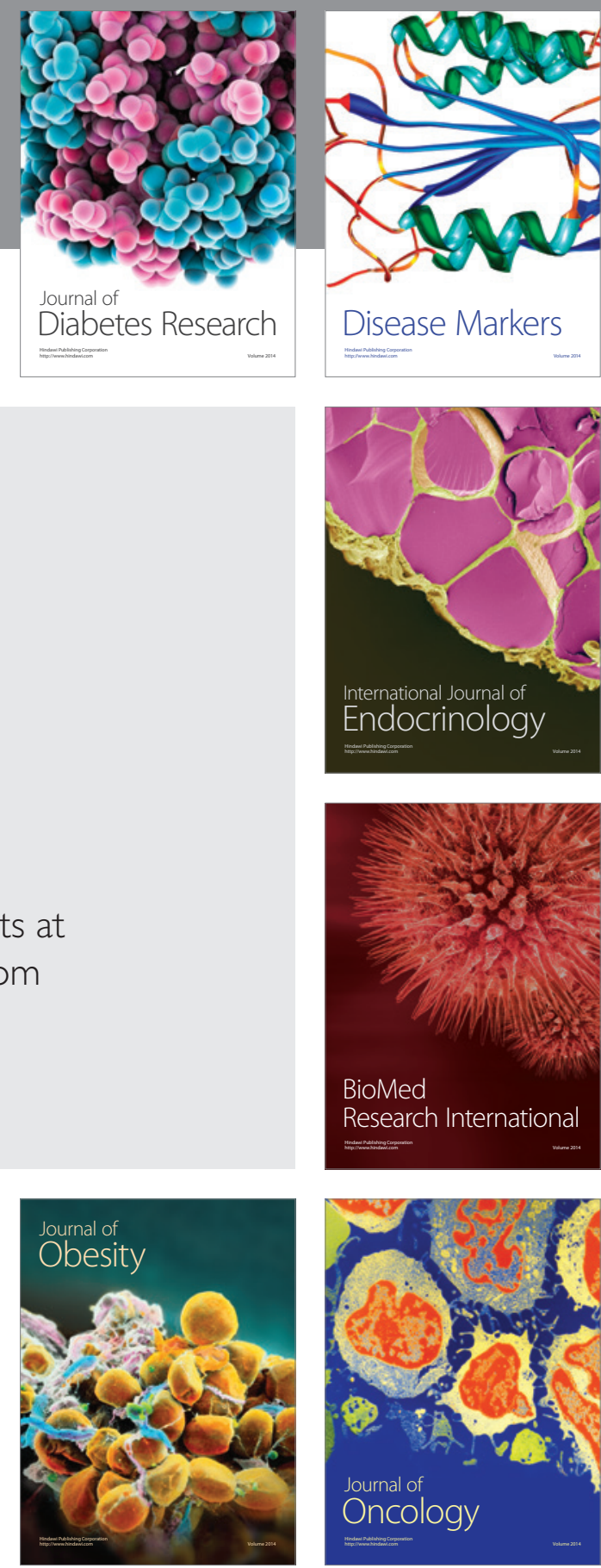

Disease Markers
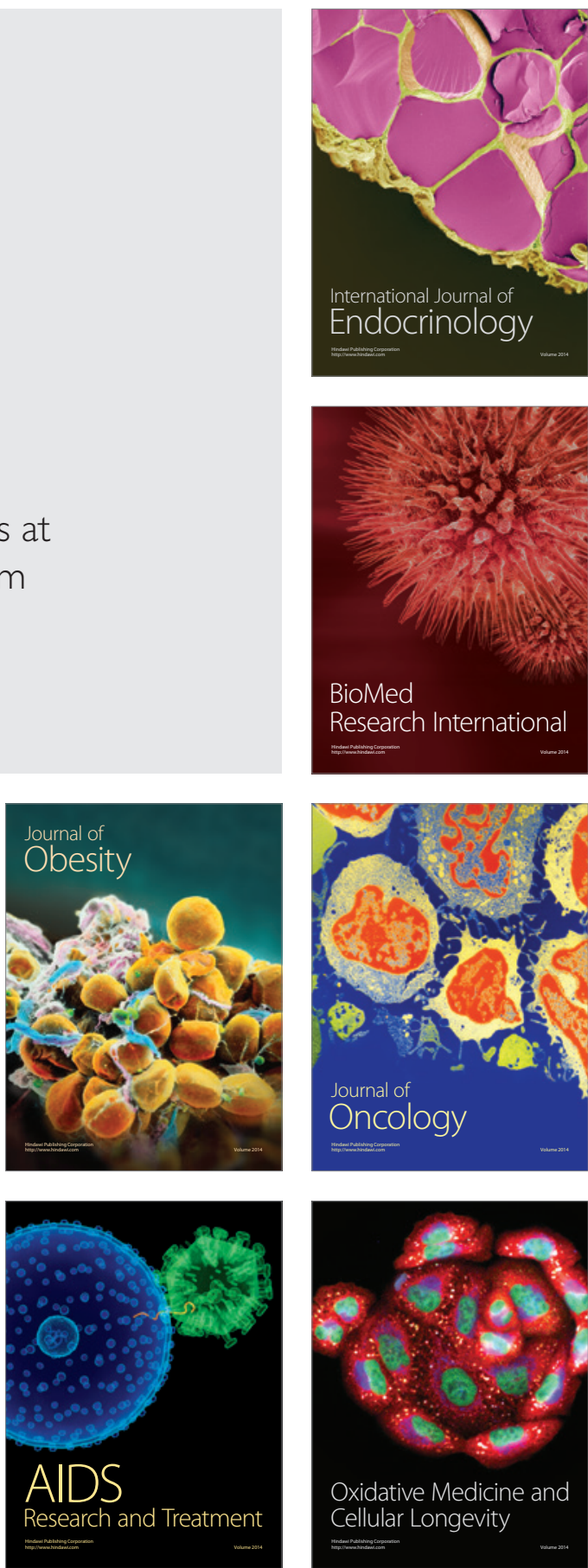